\title{
Photographic-documentary account of rural characters in three times: Pampa and Northwest, Argentine republic between the end of XIX and early XX
}

\begin{abstract}
Based on the general theory of the image, this paper presents the story that three photographs transmit from three axes that cross them: the history of the photographers who produced them, the social, political and economic context in which they arise and the photographic resources and processes available between the end of the s. XIX and early s. XX. ${ }^{1}$ For this, three photographers who represent different moments and edges of that history and experiences in our two study regions are analyzed: Esteban Gonnet, Francisco Ayerza and Salvador Debenedetti.
\end{abstract}

Keywords: documentation, photography, rural characters, Argentina
Volume 5 Issue 3 - 2020

\section{Mariel Alejandra López}

Research Institute of the Faculty of Social Sciences, Argentine Catholic University (UCA), National Council for Scientific and Technical Research (CONICET), Argentina

Correspondence: Mariel Alejandra López, Research Institute of the Faculty of Social Sciences, Argentine Catholic University (UCA), National Council for Scientific and Technical Research (CONICET), Argentina, Tel (+54II) 4349-0200(72I9), (+54| I)4144| 193, Email mariel_lopez@uca.edu.ar

Received: May 2I, 2020 | Published: June II, 2020

\section{Introduction}

According to researchers on the history of photography in the context of the history of communication, such as Ramírez Alvarado, ${ }^{1}$ photography can be an interesting material support for research from the past as they constitute a "model of representation of the reality". In this sense, they can transmit "social information" to us, as well as social "transformations" in a given socio-historical context. Understanding that photographic images constitute a "model" of representation of reality is important in all research that uses them both as an object of study and as a documentary support of a problem or topic of study. For all this, in this work, where we investigate the images taken by the first photographers who focused their gaze on rural characters in the Argentine Republic, we theoretically start from the principles and presuppositions of the general theory of the image. ${ }^{2}$ For this investigation, the documentary collections available in the City of Buenos Aires were first investigated, analyzing the entire corpus of images that represented rural characters in our country. After this search, three photographers were selected, which also allowed us to distinguish three historical moments marked by social, political and economic changes, but also by technical changes in relation to photography. After their biographical and period analysis, the documentary perception or gaze that these photographers represented in their works was analyzed, taking one of each one and presenting them in dialogue.

\footnotetext{
${ }^{1}$ This article constitutes an expanded and improved version of the research work carried out for the subject History of Photography dictated within the framework of the Diploma in Research and Conservation of Photographs that I finished in 2019 at the Faculty of Philosophy and Letters of the University from Buenos Aires.
}

\section{Brief biography of the selected photographers}

\section{Esteban Gonnet- Victor Etiènne Gonnet ${ }^{2}$ (Grenoble, France 1829-Buenos Aires, Argentina 1868)}

From New Castle, England, Gonnet emigrated to our country in 1857 aboard the Argentine First Ship. As soon as he arrived here, he worked as a public surveyor and photographer in numerous parties in the province of Buenos Aires. Along with Panunzi, Gonnet is considered one of the pioneers of urban documentary photography and the campaign. Gonnet's photographs emerged as a complement to his profession since the photographic record allowed him to obtain more details in his topographic work. ${ }^{3,4}$ In fact, in the Buenos Aires Dictionary of the time, Gonnet is effectively recognized as a surveyor ${ }^{4}$ rather than as a photographer since he does not appear in the list of photographers in that dictionary. The latter is particularly interesting as this guide refers to the profession of photographers as a "portraitist". ${ }^{5}$ The latter is particularly interesting because Gonnet is recognized in the history of photography precisely for turning away from portrait photographers to start the documentary genre, even through employment contracts. In this way, shortly after beginning his work as a photographer, Gonnet released the first album because of the negative-positive system in Argentina instead of the system called daguerreotype. Between 1864 and 1865 he made the oldest known

\footnotetext{
${ }^{2}$ Very little was known about Esteban Gonnet, only his French origin, when in 2016, the genealogist Gabriel Estévez Maillet compared the signatures of Esteban Gonnet and Victor Etiènne Gonnet, turning out to be identical. Gonnet did not use his first name, his signature corresponded to the first two letters of his ET name, plus his last name. When emigrating to Argentina he use the name Esteban, being this, the translation of the name Etiènne into Spanish.
} 
photographic views of Buenos Aires and which he incorporated into his albums called Memories of Buenos Ayres and Memories of the Buenos Ayres campaign. In addition to the landscapes, Gonnet was interested in recording country life by photographing scenes of yerra, ${ }^{3}$ roasting and cattle handling, among other activities. His photographs were the first used to make lithographs for printing in newspapers.

\section{Francisco Ayerza (Buenos Aires, Argentina I860-I90I)}

Francisco Ayerza studied at the Colegio del Salvador, law at the University of Buenos Aires and, towards the end of the s. XIX, began as an amateur in "photographic art" forming what has been considered the first artistic movement in Latin America in which photography completely replaced the characteristic painting of the $1880 \mathrm{~s}$.

He participated politically in the Revolution of the 1890 s occupying a bench in the Chamber of Deputies. At their home in the City of Buenos Aires, and together with a group of other gentlemen, "the gentlemen photographers", 6 they formed a "Society of Photography Fans" that ended up forming on 29 April 1889 the "Argentine Photographic Society of Amateurs" (SFAA). Shortly after this, this entity began its activities in it own premise located on Florida 365 street, although, when it caught fire in 1893, it later moved to Avenida de Mayo and Peru, and finally to the heights of Café Tortoni, one of the current Notable Bars of the City of Buenos Aires. This society, which also included women, began to make exhibitions of the work of its members and published a newsletter. Her fans also made photo albums that clearly eluded the subject of the portrait. Francisco Ayerza photographed, with heavy bellows cameras and wooden tripods, preferably the Argentine Pampa and its customs. Hence, he is considered one of the first costumbrista documentary photographers in the history of Argentine photography. In fact, in 1885 he tried to illustrate with his photos the famous book "Martin Fierro" for which the field where the Estancia San Juan de Pereyra (today Pereyra Iraola Park) was located, very close to the City of Buenos Aires, was chosen. Despite the enthusiasm invested in such work, he was unable to finish it because of his early death.

\section{Salvador Santiago Lorenzo Debenedetti (Avellaneda, Argentina I884-1930 Altamar)}

The son of an Italian immigrant from Piedmont and a native from the River Plate, Debenedetti lived in the Barracas al Sur neighborhood, completing his primary studies at School No. 1 in Avellaneda and his secondary ones at Colegio San José in the City of Buenos Aires. After leaving law studies, he entered the Faculty of Philosophy and Letters at the University of Buenos Aires, where he met Juan B. Ambrosetti and fully devoted himself to archeology and anthropology obtaining his doctorate in 1909. Along with him, Debenedetti participated in the first excavations at the well-known Pucará de Tilcara archaeological site (located in the Quebrada de Humahuaca, Jujuy province, northwestern Argentina) between 1908 and 1910. Later, he deepened archaeological studies at other sites in the Quebrada de Humahuaca. At the end of the 1910s he was appointed director of the Ethnographic Museum of the University of Buenos Aires, also serving as a professor at that university and at the National University of La Plata. In 1929 he was appointed a member of the Paris Society of Americanists. He died prematurely on October 1, 1930, with 46 years on board the "Cap Polonio" back to the country, after attending the Congress of Americanists in Hamburg. At those moments he was in full intellectual and productive activity. In recognition of the importance of his studies, his ashes are buried next to those of Juan B. Ambrosetti, in a monument-pyramid, the work of Martín Noel, at the foot of the Pucará de Tilcara archaeological site. Very little is known

${ }^{3}$ Yerra" is the action of marking cattle on farms with red hot iron. about him as a photographer, however, Debenedetti can be said to be one of the first researchers to document customs from what is known as "ethnographic photographs" in the context of the archaeological sites he investigated.

\section{The different photographic processes and the respective temporal, socio-political and economic contexts}

In the context of the middle of the s. XIX, Gonnet It departs from the typical studio portrait photographers who could be accessed, for the most part, by the most affluent classes in the City of Buenos Aires, although it is notable that they still pose their characters looking at the camera. Through the process of albumin on cardboard, he became one of the founders of Argentine photographic documentary ${ }^{8}$ exposing the most typical, both in relation to the landscape, and with respect to the different characters that appeared in your photographs. For the representation of rural characters, Gonnet began with a stereotyping process, both with respect to the figure of the "gaucho", as well as other rural characters and Argentine customs in general. For this, he would also have used in his photographs some objects that acted as symbols, helping to form an iconic language in the images.

Indeed, when analyzing their photos one can say that there is a composition thought out in which the characteristic elements of the portrayed characters (clothing, accessories or ornaments and other elements they carried, such as weapons or tools characteristic of the time) are also put on scene (Figure 1).

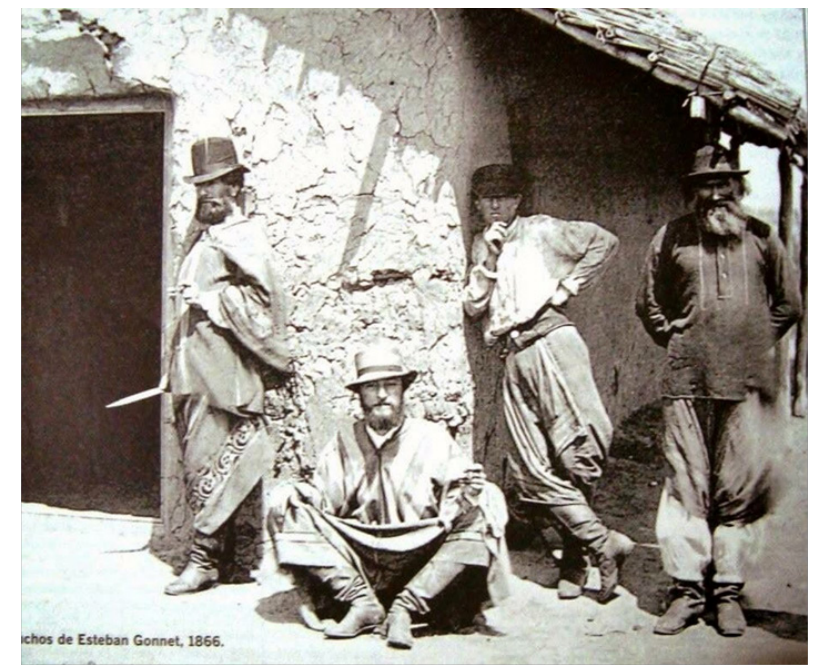

Figure I Gauchos. Gonnet 1866. Source: National Library of Buenos Aires, Argentina.

Perhaps because of its origin or its contacts, the novelty but, also, for these characteristics that are usually indicated as original in his work, his photos were sold abroad, especially in Europe, where photography from travels or distant places were gaining popularity around that time. Towards the end of the s. XIX, the appearance of negatives, or dry plaques, ${ }^{4}$ as well as the new papers to the gelatin silver bromide marked an important milestone, allowing photographers

${ }^{4}$ According to the explanation of Ramírez Alvarado 2011, what we here call dry plate due to the joint use of a solution of water, gelatin and bromide sensitized with silver nitrate on a glass plate was the successful replacement of the "collodion". The difference over this last technique and that it must have been really advantageous for the field work of the photographers in the field is that it was no longer necessary to keep the plate wet at all times and, also, as regards the photography of people the exposure time was reduced to a quarter of a second. 
who were touring the country documenting landscapes and customs to increase. In this context, Ayerza, one of the so-called "prominent men of Buenos Aires society" due to all that the practice of amateur photography implied and, even, in accordance with membership requirements established by the Statutes of the Argentine Photographic Society of Amateurs (1889), ${ }^{5}$ appears in the city of Buenos Aires as an outstanding photographer to the point of generating the SFAA in his own home, as previously stated.

In its first decade, the SFAA promoted so-called national photographs, images that represented the country's landscapes, customs, traditions and material progress, seeking to spread an optimistic vision of the country's future (Figure 2). However, although the SFAA had members outside of Buenos Aires, the vast majority of the material was about it. ${ }^{9}$

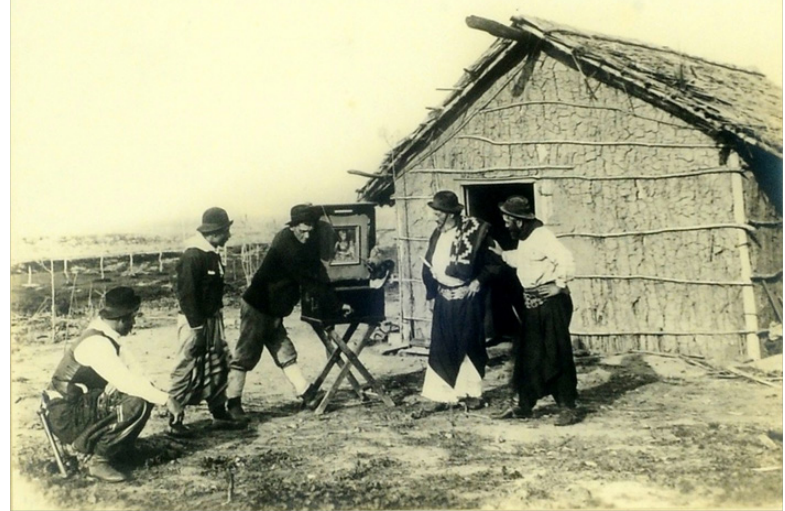

Figure 2 Ayerza. The phonograph c. 1895. Source:The great photographers, website.

In this sense, Ayerza's photos were not linked to a need generated by his basic profession, as in the case of Gonnet, nor were they necessarily commissioned. Hence, he was able to produce and assemble more artistic settings, in different locations, as well as exhibit his works, together with his associates, in exhibitions mounted by them and commented on by the newspapers of the time. In the series of photos that Ayerza took at the Estancia San Juan, in the town of Quilmes, province of Buenos Aires, you can see the setting up of different scenarios representative of the different rural characters and their customs even in the same place. Thus, in works called "Payando" c. 1891 and "Playing the trick" c. $1891,{ }^{10}$ it is possible to reconstruct in the photographer's gaze how he makes his actors pose in two nearby sectors within the same stage or landscape, thus constructing the customs scenes that he surely had in mind. During the first half of the s. XX, and continuing with the trend started at the end of the last century, it can be said that the documentary genre was installed in photography and was also appropriated by the first "researchers" of different disciplines in our country. Among many others, this was the case of Debenedetti, who arrives at one of what was one of the archaeological sites under his studies, Alfarcito. He arrived there thanks to the fact that he learned about him "from the mouth of some countrymen who know the region". ${ }^{11}$

${ }^{5}$ Tell mentions that in the copy found in the Société Française de Photographie library, there are many similarities to that of France, although the links between the two countries are unknown, and highlights, among other things, that in Article 19 the incompatibility "of the quality of active partner with that of photographer or photography employee" is mentioned.

${ }^{6}$ Recite stories or poetic compositions improvised and accompanied with the guitar.
This is precisely where he takes some photographs that go beyond his archaeological study since in the imposing landscape of the terraces of this site he includes in the photograph, and for example, a weaver together with her "indigenous" loom (Figure 3). ${ }^{11}$ These pioneering archaeological, but also anthropological-ethnographic, expeditions include a series of photographs that have been studied from various points of view for their documentary ethnographic value. ${ }^{7,12}$ These last types of documentary records on glass plates ${ }^{7}$ They closely resemble Gonnet's in that the documentation served as testimony or proof of what was being studied and lived.

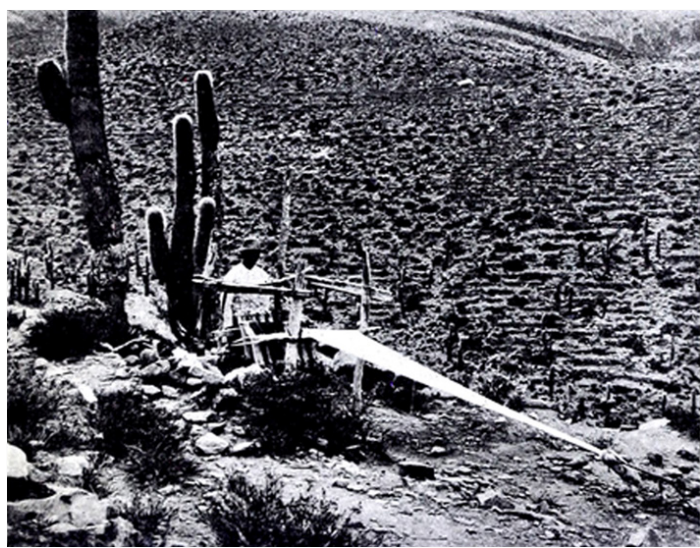

Figure 3 El Alfarcito by Debenedetti 1918: 291, figure 2.

However, in his field notebooks Debenedetti describes the findings and his link with people, marking the differences with the other, the different, the subordinate, the one who even collaborates as a hired pawn

On the other hand, and continuing with the idea of progress and modernization that Ayerza tries to introduce in his photos, Debenedetti also lets us read between the lines of his manuscripts, ${ }^{13}$ in some of his photos and even in his production academic paradoxes of the colonizers and colonized. Among them, explicitly highlights the inefficiency in the incorporation of indigenous people in the "industrialization" processes due to the lack of sufficient knowledge of the customs and aptitudes of the different groups or communities ${ }^{14}$ to be able to carry out the alleged homogenization of the NationState, ${ }^{15}$ aspects highlighted in Pegoraro's research. ${ }^{16}$ Even with all the historical, social and economic political burden in which the documentary genre appeared in Argentine photography, it could be argued that Debenedetti also suggests, at least in some of his photographs and through frames such as the one presented here, more artistic aspects or aesthetic and not just "scientific".

\section{Images in dialogue: the documentary perception or gaze of these photographers}

The selected sample considered three images as the object of study with which photographers visually communicate different aspects of rural characters in the two micro regions of our studies: pampa and northwestern Argentina, at different times between the end of (field notebooks) at the beginning of my research for my Doctoral Thesis, more specifically between 1999 and 2000, and see some of the photos of the FFyL expeditions when they were just beginning to be scanned at the Juan Bautista Ambrosetti Ethnographic Museum of the Faculty of Philosophy and Letters of the University of Buenos Aires. Hence, the copy that I present here is taken from one of her publications. 
the s. XIX and early s. XX. Within the theoretical framework already indicated, and starting from the assumption that the essential and specific component of an image is the iconic one, and that for this reason the image can refer to events that imply "a selection of reality, a repertoire of specific elements of representation and a system of order of such elements", ${ }^{2}$ the link between the three images is limited in this work to bring into play the perception of rural characters by each of these photographers and their representation. This is because this theoretical framework considers that both perception and representation constitute two processes that allow objectifying the nature of the photographic image in order to be able to analyze it, which is not the same as saying that photography reproduces "reality" without intervention of the "hand", ${ }^{1}$ and perception of the photographer.

\section{Trimming reality}

Both in terms of perception and representation of rural areas, the three photographers are dominated by the realistic model. A benchmark model since the Renaissance and that allows them to be positioned in our history as founders of photo-documentary. In this sense, the three photographers would have contributed to photo-documentary in our country by producing photographic images that "represent" the history of rural characters as "an objective and incontrovertible fact" (in the sense that Villafañe and Mínguez give it). ${ }^{2}$ Notwithstanding this, from the position of observers, including ours, the reality of his photographs is perceived as "an iconically modeled reality" (in the sense that Villafañe and Mínguez gives). ${ }^{2}$ This is to say, a reality built following representative models based on "mimesis", especially with regard to "space" and "perspective" (in terms of Gombrich); ${ }^{17}$ which still brings them quite close to the "psychology of pictorial representation" of the time.

\section{Repertoire of specific elements of representation and their order system}

Even assuming that these three photographers frame their work within a representative "realistic" model based on mimesis, following the aforementioned authors, it is also interesting to argue that this model acted, predominantly but not exclusively, in a similar way to historical conventions and cultural in general. ${ }^{2}$ It follows that, although the specific elements of representation of the characters in these photos generally accompany historical conventions, which we can also observe in paintings of the time or read in what the books about the figure of the gaucho narrate, both from research (for example, Rodríguez Molas) ${ }^{18}$ and from retrospective views of the world of Martin Fierro, ${ }^{19}$ it is also possible that within the repertoire of representation elements unconventional elements such as the phonograph in the photo selected here from Ayerza. In the case of this last photographer, it could be said that in the pre-iconic order or scheme, which is the one "halfway between perception and representation", ${ }^{2}$ it would already be operating a kind of montage of the city and the interior of the domestic space on a scene that, from the point of view of the iconic structure, would be basically rural However, as with the other two examples, the three photographers achieve a syntax of elements that represent in space and time the reality referred to at the time in the different locations photographed. In this sense, and returning to Ayerza's photography, the phonograph and whoever handles it clearly overlap the syntactic articulation of the elements of the representation of the same nature (ranch, field, trees, rural characters, clothes, accessories, among the main) and in which it would not be expected to observe a phonograph managed by a character who, due to his clothing, fits more into a city scene than with the "gauchos" who watch him along with two other rural characters. $^{8}$

Despite this freedom that we could link, perhaps, with Ayerza's most artistic touch, in the three photos not only does the convention appear in the representation but also a representation structure that seems to keep a balance in the connection of the elements represented. In this sense, the representation of specific elements to the different rural characters (the pampa gaucho and its variants, according to their different modalities and tasks, as well as the northern weaver) can be observed, which are significant both in the regional context and in the national. Photo documentary in our country is born knowing that photography is never reality but an image that is a model of reality, even when there is a high level of iconicity and or there has been an influence of the photographer on the intended visual result to look for a representation or image as specular as possible, such as could have been the case of Gonnet due to his profession. As anthropologists, historians or archaeologists of historical times in search of documents, photographs should be approached considering the particularities of the image in order not to fall into false histories or, in any case, in order to understand the complex reality and times of the photographer, along with the limitations of his technique and speech. But it also happens that contemporary photo documentary contemplates all these edges and expressive freedoms of the author and researchers must accept the challenge of dealing with it all. ${ }^{20-25}$

\section{Conclusion}

The documentary photographic account presented in this triad allows us to think that these images, which are equivalent to many others, are representative, photographic perceptions through, of the Argentine "reality" for the period analyzed. This documentary account aims, mainly, at the construction of a discourse that begins at the end of the s. XIX and imposed at the beginning of the s. XX accompanying the so-called process of formation of the National State in our country. Within this process, it is necessary to show the different realities in order to know them and incorporate them into the National State, even if it is not from the point of view of another, pre-existing one. In these senses it is understood the need to entrust in the hands of some photographers the "work" of reflecting the different "realities", both in the so-called "campaign" of Buenos Aires, and in the city of Buenos Aires; as well as the need to show it in different circles and through different media. If, as Villafañe and Mínguez maintain: “... any image maintains a link with reality regardless of the degree of similarity or fidelity that it maintains with it.", ${ }^{2}$ the photographic image, like others, It can also be considered as an important document to analyze in itself and from various perspectives and theoretical frameworks. Indeed, photography can show us elements that were actually used (material culture) as well as customs (immaterial culture) of a certain time and place, but it can also show us modeled elements, a whole modeled reality. On the other hand, we are aware that, from the artistic or image analysis point of view, this work could delve much further with respect to each of the photographic techniques as well as the representation resources of the period highlighted here. But this would exceed our objective focused on showing how and with whom photo-documentary is born in our country in regards to the areas and landscapes that are part of our case studies: the Argentine pampa and the northwest.

${ }^{8} \mathrm{We}$ are aware that this differentiation between rural characters is questionable and it is not the objective of this work to delve into the representative elements of the "gaucho" due to a question of space. 


\section{Acknowledgments}

None.

\section{Funding}

None.

\section{Conflicts of interest}

Author declares that there is no conflict of interest.

\section{References}

1. Ramírez Alvarado, María del Mar. El valor de la fotografía como objeto de estudio y en las investigaciones sobre comunicación: Reflexiones teóricas. Discursos fotográficos Londrina. 2011; 7: 55-76.

2. Justo Villafañe Gallego, Norberto Mínguez Arranz. Principios de Teoría General de la Imagen. Madrid: Pirámide. 2002.

3. Alexander, Abel and Príamo, Luis. Buenos Aires City and Campaign Photographs by Esteban Gonnet, Benito Panunzi and others. 1860-1870. Buenos Aires: Antorchas Foundation, 2000.

4. Masán, Lucas, A. Memory as a modern life experience. Gonnet's photographs were in Buenos Aires in 1860. Estudios del ISHIR, Rosario. 2017;19:65-81.

5. Pillado, Antonio. Dictionary of Buenos Aires, that is, a guide for outsiders. Printing to come: Buenos Aires, 1864.

6. Tell, Verónica Gentlemen, gauchos and modernization. A reading of the project of the Argentine Photographic Society of Amateurs. CAIANA Magazine of Art History and Visual Culture of the Argentine Center of Art Researchers (CAIA). 2013;3:1-19.

7. Carrasco, Morita; Costilla, Julia; Estruch, Dolores and Wahren Cecilia The construction of stories and memories through ethnographic photographs: an interdisciplinary reading. Anthropology Notebooks, Buenos Aires, 2014. p. 159-174.

8. Alexander, Abel and Príamo, Luis. Buenos Aires City and Campaign. Photographs by Esteban Gonnet, Benito Panunzi and others. 1860-1870. Buenos Aires: Antorchas Foundation, 2000.

9. Príamo, Luis; Alexander, Abel; Gorelik, Adrián and Goretti, Mateo. Buenos Aires: History of the streets and their names. Ceppa Foundation: Buenos Aires, 2015.
10. Príamo, Luis and Deferrari, Second. Francisco Ayerza. Creole Portraits. Las Lilas Foundation: Buenos Aires, 2017.

11. Debenedetti Salvador. The pre-Hispanic ruins of El Alfarcito. Bulletin of the National Academy of Sciences, Córdoba, 1918. p. 287-318.

12. Costilla, Julia; Drigo, Ana Laura; Estruch, Dolores; Hopp, Verónica and Matera, Sebastian Photography as an anthropological source: an approach to the analysis of the visual production of the ethnographic and archaeological campaigns in the Argentine Northwest (1880-1930). IX Argentine Congress of Social Anthropology. Faculty of Humanities and Social Sciences. National University of Misiones: Posadas; 2008

13. Debenedetti, Salvador. XIV Archaeological Expedition of the Faculty of Philosophy and Letters. Handwritten travel book available in Buenos Aires, FFyL Ethnographic Museum, UBA. 1917/1918.

14. Debenedetti Salvador. The submission of the Chaco Indians: the religious factor, military and industrial. 1909;1(3):359-370.

15. Debenedetti Salvador. Nationalism in teaching. Lecture delivered by doctor Don salvador Debenedetti. At the Teatro Roma de Avellaneda, to benefit the Roque Sáenz Peña library. 1915. 18 p.

16. Pegoraro Andrea. The collections of the Ethnographic Museum of the University of Buenos Aires: an episode in the history of Americanism in Argentina 1890-1927. Buenos Aires, Doctoral thesis, FFyL; 2009.

17. Gombrich Ernst Hans. Art and illusion. Study on the psychology of pictorial representation. Barcelona: Gustavo Gilli, 1979.

18. Rodríguez Mola, Ricardo E. Social history of the gaucho. Ediciones Marú: Buenos Aires. 1968.

19. Testa Analía H. Gaucho corner. Anthology of the Supplement Campo de La Nación. Emecé, Buenos Aires, 2004.

20. Francisco Ayerza.

21. Great photographers.

22. Gonnet Catalog.

23. Catalog Photos of America.

24. South American photographers.

25. First views of Buenos Aires. Photographs by Esteban Gonnet. Buenos Aires 1864. National Library: Buenos Aires. 2009. 